\title{
Optimization of Dry Ashing of Whole Blood Samples for Trace Metal Analysis
}

\author{
Stefanie A. Bragg, Zi-Ling Xue \\ Department of Chemistry, The University of Tennessee, Knoxville, USA \\ E-mail:xue@ion.chem.utk.edu \\ Received July 20, 2011; revised September 14, 2011; accepted October 3, 2011
}

\begin{abstract}
Dry ashing is an established method. Ashing whole blood samples are, however, often difficult to carry out with significant sample loss, and the procedure is not well documented. A new procedure has been developed and optimized to dry-ash whole blood samples for trace metal analyses. The procedure reduces both the dry-ashing time by more than two thirds and sample loss. The ashed sample can be readily used in subsequent, simultaneous or individual analysis of several metals by ICP-OES, as demonstrated in the analysis of a whole blood sample. The new procedure is simple, inexpensive, and faster than the established method.
\end{abstract}

Keywords: Dry Ashing, Blood Samples, Trace Metal Analysis

\section{Introduction}

Elemental analysis is one of the mostly widely used methods in chemical analysis, and much progress has been made to analyze [1-3]. Ashing procedures have long been used to pretreat complex samples such as biological tissues and fluids prior to elemental analysis [4-13]. Dry ashing in particular has been a standard in the analysis of many biological samples, and it has been used as a benchmark in the development of new analyticcal methods [9-12,14-23] with many citations in this year alone [15-20]. Other techniques have been used as well but these are either expensive $[4,6]$ or more ideal for identifying specific elements $[5,8,13,24]$. Microwave digestion has recently found use for pretreatment. But it requires costly instrumentation and like wet digestion, the sample size it handles is small, usually ten grams or less $[25,26]$. In comparison to wet or microwave digestion, dry ashing is an inexpensive method that allows for multiple elemental analyses in one sample without the addition of chemical interferrents. In particular, dry ashing allows occasional users to analyze biological samples without the use of costly instrumentation. Its most attractive feature, though, is the ability to preconcentrate samples for detection of trace metals.

During our recent studies of new analyses for trace chromium in blood, we have found that while there is still prevalent use of dry ashing for these samples there are few guidelines to follow [9-12]. The lack of stan- dardization and temperature monitoring for dry ashing of blood samples leads to a long process (often several days) with significant sample loss. We have developed a new dry ashing process with the use of thermocouples. The temperature of the process is elevated in a gradient manner but without the need of a muffle furnace. This new, optimized process significantly reduces the dry ashing time and sample loss. By using an inductively coupled plasma-optical emission spectroscopy (ICP-OES) analyzer, we have used the dry ashing for the analyses of trace metals in blood samples. The development of this new process for dry ashing of whole blood samples is reported here.

\section{Experimental}

Ceramic evaporating dishes, Pyrex watch glasses, high purity grade nitric acid, potassium oxalate, copper AA and zinc AA standards were purchased from Fisher Scientific, Pittsburgh, PA. Chromium and iron AA standards were purchased from Sigma-Aldrich, St. Louis, MO. Vanadium AA standard was purchased from Ricca Chemical Company, Arlington, TX. Molybdenum AA standard was purchased from High-Purity Standards, Charleston, SC. Whole blood samples (porcine) were obtained from Wampler's Farm Sausage, Lenoir City, TN. Samples were collected in Nalgene bottles using potassium oxalate as anti-coagulant. Trace metal detection was performed using a Perkin Elmer ICP-OES Optima 2100 DV. 


\subsection{Method A (New Procedure)}

Whole blood (40.1 - $71.3 \mathrm{~g})$ was placed in a ceramic evaporating dish, covered with a watch glass, and placed on a hot plate at $80^{\circ} \mathrm{C}-100^{\circ} \mathrm{C}$ in order to evaporate water in the sample slowly without bumping or boiling. Upon evaporation of water, the dish was transferred to a Bunsen burner and heated slowly with a cool flame $\left(250^{\circ} \mathrm{C}-300^{\circ} \mathrm{C}\right)$ initially in order to avoid boiling and bumping. After $30 \mathrm{~min}$, the temperature of the flame was increased to $450^{\circ} \mathrm{C}$ and the sample was heated continuously for several hours. Intermittent stirring allowed even ashing and monitoring of the sample. Ashing was determined complete when the sample was a rust red-brown color, typical for iron oxides, and no black substance, indicating carbon, remained [21,22]. Total ashing time was dependent on the volume of sample in the evaporating dish.

Standard additions for the detection of chromium by ICP-OES was used in the current work. Thus this new procedure was performed 5 times using $223 \mathrm{~g}$ of whole blood in order to obtain sufficient ash (2.44 g).

\subsection{Method B (Established Procedure) [23]}

In the current work, the reported method was slightly modified by using parallel steps as in the new method. This is not the recommended procedure.

The following was conducted for comparison with the new procedure (Method A). Whole blood (40.1 g) was placed in a crucible and placed on a hot plate at $80^{\circ} \mathrm{C}$ $100^{\circ} \mathrm{C}$ in order to evaporate water in the sample. After 8 $\mathrm{h}$, the crucible was transferred to a Bunsen burner and heated slowly with a cool flame. After $90 \mathrm{~min}$, the temperature of the flame was increased to $450^{\circ} \mathrm{C}$ and the sample was heated continuously for several hours. Ashing was determined complete when the sample was a rust red-brown color, typical for iron oxides, and no black substance, indicating carbon, remained [21,22].

\subsection{Elemental analysis using ICP-OES}

The ash (2.44 g) was dissolved in high purity concentrated nitric acid $(50 \mathrm{~mL})$ and heated. This solution was divided into $10 \mathrm{~mL}$ aliquots and each diluted to $100 \mathrm{~mL}$. Samples were spiked with chromium and vanadium and standard addition was performed [27]. For the determination of iron, a $1 \mathrm{~mL}$ aliquot of the diluted sample was taken and diluted further to $100 \mathrm{~mL}$ using a $5 \%$ nitric acid solution. Calibration standards were used for the determination of iron, copper, zinc, manganese and molybdenum. The concentrations of iron, copper, zinc, chromium, manganese, vanadium and molybdenum in the ash samples were determined using ICP-OES. Each sample was repeated three times in order to obtain standard deviations.

\section{Results and Discussion}

As a bench mark in elemental analysis, dry ashing is inexpensive, and can be easily conducted in chemical laboratories. Dry ashing has been under scrutiny, but one cannot deny its simplicity and cost effective qualities. Arguments such as possible sample loss, reaction with the container's surface, and incomplete ashing have been presented $[23,28]$. Yet many still regard dry ashing as a viable practice provided care is taken in the process [9-12,14,21,22,29].

In the last century, attempts have been made to establish a uniform process for the pretreatment of samples prior to metal detection. Despite efforts, only general guidelines were formulated with specific details for various samples. Middleton and Stuckey summarized previous studies using either dry or wet methods for some metals and recommended a temperature range of $500^{\circ} \mathrm{C}-550^{\circ} \mathrm{C}$ [30]. Gorsuch and Thiers elaborated on this, adding more comprehensive information for additional metals based on ashing of numerous samples [31,32]. In order to form a collective view of these methods, the Analytical Methods Committee published "Methods for the Destruction of Organic Matter" discussing wet and dry decomposition [24]. In this article, guidelines still in practice today were outlined for dry ashing and advantages of the technique over wet digestion were established. Even in more recent works, only general guidelines are regarded and little uniformity is seen. Tidehag and co-workers dry-ashed blood samples for a total of $48 \mathrm{~h}$ but did not disclose details or mention the total ash obtained [29]. Dry ashing allows for most common metals to be analyzed. The lack of additional reagents prevents interferences in a blank during analysis. A larger quantity of sample can be analyzed, but perhaps the most attractive trait of all is the small amount of attention required for ash samples to be completed [24].

After much experience with ashing blood, we have developed a new procedure that uses a ceramic evaporating dish and Pyrex watch glass cover rather than a standard crucible and lid. Such a design allows for increased air exposure to the sample to increase the ashing rate. With the use of a thermocouple, the ashing temperature has been closely controlled, leading to minimum sample loss and much faster ashing time in comparison to the control process that uses a reported crucible system. All other variables remain consistent and are given in detail, including initial evaporation time, ashing times, temperatures, and overall yields (Table 1). The volume 
of blood to be dry-ashed depends on the size of the evaporating dish. With our equipment, as much as 50 $100 \mathrm{~mL}$ of blood could be dry-ashed in one procedure.

Closely controlling the ashing temperature has also been found to prevent sample loss and cross reaction with the container. Additionally, the temperature was elevated gradually. Thus, careful monitoring of the temperature is recorded in the current work in association with the ashing time at a specific temperature. Maximum temperature was no higher than $500^{\circ} \mathrm{C}$ in order to prevent any possible volatilization of metals as well as reaction with the crucible container [30].

Another key improvement in the current procedure is the use of a ceramic evaporating dish with a Pyrex watch glass as a cover rather than a ceramic crucible and lid. This modification leads to an increase in the air flow over the sample, allowing for a significantly shorter total ashing time. Sufficient supply of $\mathrm{O}_{2}$ in the air flow is believed to increase the rate of the oxidization of organic materials in the heated sample, leading to their conversion to $\mathrm{CO}_{2}$ and reducing the ashing time. We have conducted control studies to better demonstrate the improvement of this system in comparison to the literature procedure using a crucible (and lid) and Bunsen burner. Two experiments were performed using the same burner and the same mass of whole blood, except that one used a ceramic evaporating dish with a Pyrex watch glass (Method A), and another used a crucible and lid as control (Method B). To the dish and the crucible, whole blood $(40.1 \mathrm{~g})$ was added to each. Each apparatus was set on the hot plate and allowed to evaporate water at $80^{\circ} \mathrm{C}$ for $8 \mathrm{~h}$. Initial heating on the burner was allowed. The sample in the crucible, however, required both an extra hour of low heat and close monitoring, as its sample under the lid, spilled over from the inside. After $30 \mathrm{~min}$ of low heat $\left(250^{\circ} \mathrm{C}-300^{\circ} \mathrm{C}\right)$, the evaporating dish/watch glass system was increased to $450^{\circ} \mathrm{C}$. With intermittent stirring the total ashing time was $18 \mathrm{~h}$ for the new procedure (Method A). Under the same conditions the crucible system in the control (Method B) required a total of $55 \mathrm{~h}$ of ashing. The control using the reported procedure (Method B) leads to at least $11 \%$ loss of the ash product. A comparison of both methods is summarized in Table 1.

In addition to avoiding sample loss, the new procedure (Method A) allows for the sample to be completely ashed in less than one-third of the time used in the control (Method B). It also involves less work. We have also used the new method to ash, in one procedure, more blood samples than the reported procedure using a crucible $[4,23]$. This is a very attractive feature, especially when examining trace metals. If a smaller amount of blood is needed to be ashed in, e.g., the analysis of abun-
Table 1. Ashing times and yields of evaporating dish and crucible.

\begin{tabular}{lcccc}
\hline & $\begin{array}{c}\text { Evaporation } \\
\text { period (h) }\end{array}$ & $\begin{array}{c}\text { Initial heating } \\
\text { period (h) }\end{array}$ & $\begin{array}{c}\text { Ashing } \\
\text { period (h) }\end{array}$ & $\begin{array}{c}\text { Ash } \\
\text { mass (g) }\end{array}$ \\
\hline Method A & 8 & 0.5 & 18 & 0.4123 \\
$\begin{array}{c}\text { Method B } \\
\text { (Control) }\end{array}$ & 8 & 1.5 & 55 & 0.3705 \\
\hline
\end{tabular}

Table 2. Analysis of metals in dry-ashed whole blood.

\begin{tabular}{cc}
\hline Element & Concentration \\
\hline $\mathrm{Fe}$ & $298.1 \pm 5.8 \mathrm{ppm}$ \\
$\mathrm{Zn}$ & $272 \pm 14 \mathrm{ppb}$ \\
$\mathrm{Cu}$ & $169.4 \pm 1.7 \mathrm{ppb}$ \\
$\mathrm{Cr}$ & $8.71 \pm 1.7 \mathrm{ppb}$ \\
$\mathrm{Mn}$ & below limit of detection \\
$\mathrm{V}$ & below limit of detection \\
$\mathrm{Mo}$ & \\
\hline
\end{tabular}

dant metals, the new procedure using an evaporating dish can be completed in shorter time than $18 \mathrm{~h}$.

To demonstrate both abundant and trace analysis, the concentrations of iron, copper, zinc, chromium, manganese, vanadium and molybdenum were determined from the same blood sample using ICP-OES. Results are shown in Table 2.

\section{Conclusions}

Dry ashing is a valid pretreatment technique that has been used as a benchmark for other methods [4]. The current work reports a new dry ashing procedure that can be implemented in any lab setting. Many metals may be detected at once or individually. The method is simple, inexpensive, and faster than the established procedure. The dry ashing of blood samples using the new procedure may help set a precedent for dry ashing of other samples.

\section{Acknowledgements}

The authors thank the US National Institutes of Health (1R01DK078652-01A2) for financial support and Wampler's Sausage Farm, Lenoir City, Tennessee, for providing the porcine blood samples.

\section{References}

[1] D. T. Burns, "Precursors to and Evolution of Elemental Organic Tube Combustion Analysis over the Last Two 
Hundred Years," Analytical Procedures, Vol. 30, No. 6, 1993, pp. 272-275. doi:10.1039/ap9933000272

[2] J. Cholak and D. M. Hubbard, "Spectrographic Determination of Beryllium in Biological Material and in Air," Analytical Chemistry, Vol. 20, No. 1, 1948, pp. 73-76. doi:10.1021/ac60013a020

[3] J. Sysalova and V. Spevackova, "A Study of Sample Mineralization Methods for Arsenic Analysis of Blood and Urine by Hydride Generation and Graphite Furnace Atomic Absorption Spectrometry," Central European Journal of Chemistry, Vol. 1, No. 2, 2003, pp. 108-120. doi:10.2478/BF02479263

[4] J. Versieck and L. Vanballenberghe, "Determination of Tin in Human Blood Serum by Radiochemical Neutron Activetion Analysis," Analytical Chemistry, Vol. 63, No. 11, 1991, pp. 1143-1146. doi:10.1021/ac00011a016

[5] G. Cobo, M. Gomez, C. Camara and M. A. Palacios, "Determination of Fluoride in Complex Liquid Matrices by Electrothermal Atomic Absorption Spectrometry with in-Furnace Oxygen-Assisted Ashing," Microchimica Acta, Vol. 110, No. 1-3, 1993, pp. 103-110. doi:10.1007/BF01243991

[6] L. Vesterberg and T. Bergstrom, "Determination of Cadmium in Blood by Use of Atomic Absorption Spectroscopy with Crucibles-and a Rational Procedure for DryAshing," Clinical Chemistry, Vol. 23, 1977, pp. 555-559.

[7] G. Nise and O. Vesterberg, "Blood Lead Determination by Flameless Atomic Absorption Spectroscopy," Clinica Chimica Acta, Vol. 84, No. 1-2, 1978, pp. 129-136. doi:10.1016/0009-8981(78)90485-0

[8] C. J. Price, P. L. Strong, F. J. Murray and M. M. Goldberg, "Blood Boron Concentrations in Pregnant Rats Fed Boric Acid Throughout Gestation," Reproductive Toxicology, Vol. 11, No. 6, 1997, pp. 833-842. doi:10.1016/S0890-6238(97)00067-1

[9] K. Bukhave, A. Sørensen and M. Hansen, “A Simplified Method for Determination of Radioactive Iron in WholeBlood Samples," Journal of Trace Elements in Medicine and Biology, Vol. 15, No. 1, 2001, pp. 56-58. doi:10.1016/S0946-672X(01)80027-4

[10] W. Jiang, H. Tong, Z.-C. Liu, K. Wang, B.-C. Chen and C.-H. Li, "Determination of Whole Blood Lead by Dry Ashing-GFAAS," Chinese Journal of Health Laboratory Technology (Zhongguo Weisheng Jianyan Zazhi), Vol. 18, No. 3, 2008, pp. 464-465.

[11] L. Cao and Y. He, "Determination of Blood Lead and Cadmium Levels by Dry-Ash Graphite Furnace Atomic Absorption Spectrometry," Occupation and Health (Zhiye Yu Jiankang), Vol. 24, No. 23, 2008, pp. 2536-2537.

[12] J. Titze, H. Krause, H. Hecht, P. Dietsch, J. Rittweger, R. Lang, K. A. Kirsch and K. F. Hilgers, "Reduced Osmotically Inactive $\mathrm{Na}$ Storage Capacity and Hypertension in the Dahl Model," American Journal of Physiology-Renal Physiology, Vol. 283, No. 1, 2002, pp. F134-F141.

[13] K. Drábek and J. Kalousková, “Comparison of Recoveries of Inorganic and Organic Incorporated 75-Se by Four Mineralization Methods of Biological Material," Journal Radioanalytical and Nuclear Chemistry, Vol. 119, No. 2,
1987, pp. 119-129. doi:10.1007/BF02169840

[14] J. Titze, J. Rittweger, P. Dietsch, H. Krause, K. H. Schwind, K. Engelke, R. Lang, K. A. Kirsch, F. C. Luft and K. F. Hilgers, "Hypertension, Sodium Retention, Calcium Excretion and Osteopenia in Dahl Rats," Journal of Hypertension, Vol. 22, 2004, pp. 803-810. doi:10.1097/00004872-200404000-00024

[15] J. Bian, X. Zhang and W. Ni, "Determination of Aluminum in Flour Products by Microwave Digestion/Dry Ashing-Spectrophotometry," Chemistry Research (Huaxue Yanjiu), Vol. 22, No. 2, 2011, pp. 61-64.

[16] V. M. Tomovic, L. S. Petrovic, M. S. Tomovic, Z. S. Kevresan, M. R. Jokanovic, N. R. Dzinic and A. R. Despotovic, "Cadmium Levels of Kidney from 10 Different Pig Genetic Lines in Vojvodina (Northern Serbia)," Food Chemistry, Vol. 129, No. 1, 2011, pp. 100103. doi:10.1016/j.foodchem.2011.04.032

[17] C. R. Brown, K. G. Haynes, M. Moore, M. J. Pavek, D. C. Hane, S. L. Love, R. G. Novy, J. C. Miller Jr., "Stability and Broad-Sense Heritability of Mineral Content in Potato: Zinc," American Journal of Potato Research, Vol. 88, No. 3, 2011, pp. 238-244. doi:10.1007/s12230-011-9188-1

[18] N. Sogabe, R. Maruyama, O. Baba, T. Hosoi and M. Goseki-Sone, "Effects of Long-Term Vitamin K1 (Phylloquinone) or Vitamin K2 (Menaquinone-4) Supplementation on Body Composition and Serum Parameters in Rats," Bone, Vol. 48, No. 5, 2011, pp. 1036-1042. doi:10.1016/j.bone.2011.01.020

[19] A. L. R. M. Rossete, J. M. T. Carneiro, H. H. Batagello, J. G. G. Oliveira and J. A. Bendassolli, "Spectrophotometric Determination of Sulfur in Plants Using Dry Ash Oxidation and Alkaline Oxidizers," Quimica Nova, Vol. 34, No. 2, 2011, pp. 341-343. doi:10.1590/S0100-40422011000200030

[20] J. Vogl, M. Rosner and W. Pritzkow, "Development and Validation of a Single Collector SF-ICPMS Procedure for the Determination of Boron Isotope Ratios in Water and Food Samples," Journal of Analytical Atomic Spectrometry, Vol. 26, No. 4, 2011, pp. 861-869. doi:10.1039/c0ja00220h

[21] L. Yong, K. C. Armstrong, R. N. Dansby-Sparks, N. A. Carrington, J. Q. Chambers and Z. Xue, "Quantitative Analysis of Trace Chromium in Blood Samples. Combination of the Advanced Oxidation Process with Catalytic Adsorptive Stripping Voltammetry," Analytical Chemistry, Vol. 78, No. 21, 2006, pp. 7582-7587. doi:10.1021/ac060707p

[22] R. N. Dansby- Sparks, R.-Z. Ouyang and Z.-L. Xue, "Optical and Electro-Chemical Sol-Gel Sensors for Inorganic Species," Science in China Series B: Chemistry, Vol. 52, No. 11, 2009, pp. 1777-1788. doi:10.1007/s11426-009-0278-6

[23] R. Bock, "A Handbook of Decomposition Methods in Analytical Chemistry," International Textbook Company, Glasgow, 1979.

[24] Analytical Methods Committee, "Methods for the De- 
struction of Organic Matter," Analyst, Vol. 85, 1960, pp. 643-656. doi:10.1039/an9608500643

[25] P. F. E. Van Montfort, J. Agterdenbos and B. A. H. G. Juette, "Determination of Antimony and Tellurium in Human Blood by Microwave Induced Emission Spectrometry," Analytical Chemistry, Vol. 51, No. 9, 1979, pp. 1553-1557. doi:10.1021/ac50045a045

[26] A. Ferrando, N. Green, K. Barnes and B. Woodward, "Microwave Digestion Preparation and ICP Determination of Boron in Human Plasma," Biological Trace Element Research, Vol. 37, 1993, pp. 17-25. doi:10.1007/BF02789398

[27] D. C. Harris, "Quantitative Chemical Analysis," Macmillan, 2003.

[28] P. Mader, J. Száková and E. Curdová, "Combination of Classical Dry Ashing with Stripping Voltammetry in Trace Element Analysis of Biological Materials: Review of Literature Published after 1978," Talanta, Vol. 43, No. 4, 1996, pp. 521-534. doi:10.1016/0039-9140(95)01793-3
[29] P. Tidehag, G. Hallmans, K. Wing, R. Sjöström, G. ÅGren, E. Lundin and J. Zhang, "A Comparison of Iron Absorption from Single Meals and Daily Diets Using Radio Fe $\left(\mathrm{Fe},{ }^{59} \mathrm{Fe}\right)$," British Journal of Nutrition, Vol. 75, 1996, pp. 281-289. doi:10.1079/BJN19960130

[30] G. Middleton and R. E. Stuckey, "The Preparation of Biological Material for the Determination of Trace Metals. Part I. A Critical Review of Existing Procedures," Analyst, Vol. 78, 1953, pp. 532-542. doi:10.1039/an9537800532

[31] T. T. Gorsuch, "Radiochemical Investigations on the Recovery for Analysis of Trace Elements in Organic and Biological Materials, Report to the Analytical Methods Committee by the Society's First Analytical Chemistry Research Scholar," Analyst, Vol. 84, 1959, pp.135-173. doi:10.1039/an9598400135

[32] R. E. Thiers, "Contamination in Trace Analysis and Its Control," Methods of Biochemical Analysis, Vol. 5, 1957, pp. 273-335. doi:10.1002/9780470110218.ch6 